\title{
No more protection
}

\author{
Cutting NASA's science budgets is one thing; rejecting the agency's historic role in the study of Earth is \\ something else entirely.
}

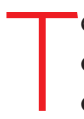
en years ago this month, NASA scientists found possible evidence for life on Mars in a meteorite, kick-starting the nascent discipline of astrobiology (Science 273, 924-930; 1996). That particular evidence has not stood the test of time, and the infant discipline has also disappointed some.

But the astrobiological vision of a Universe that had a role for biology as well as for chemistry and physics was a powerful one. It linked the study of some 4 billion years of life on Earth with a yearning for hints of life beyond. It was a vision that balanced the outward urge to explore space with an inward appreciation of the sort of world from which we set out and to which we come home. This is the sort of balance that NASA needs today - and which, to judge from a contentious change in the space agency's mission statement, its leadership seems happy to lose.

The agency's current priority, set by President George W. Bush and so far acquiesced to by Congress, is to inaugurate a new age of human exploration. This effort, by no means assured of success, will require cuts in spending elsewhere. Science - never NASA's core concern, nor ever meant to be - has suffered as a result. The most recent potential victim is scientific research on the International Space Station, which the agency seems to have considered putting on hold for a couple of years.

Congress will probably safeguard this particular programme (see page 492), although that will be no great victory. The value of the science slated for the station is not high, and pretty much every scientist outside the microgravity community could imagine better ways of spending the money (not that they will see any of it). It could be cogently argued that, if such cuts help to get the space station finished and the space shuttle grounded for good, they would be a price worth paying. Other shifts at the agency - most noticeably its decision to remove Earth science from the front of its mission statement — are far more disturbing.

\section{Look back in wonder}

President Bush's call for human exploration of the Solar System's more accessible deserts is described as a "vision for space exploration", but this puts the cart before the horse. Although NASA needs direction and leadership, it is a producer of visions as much as their consumer. The Apollo programme, for example, provided a vision of America at its 'can do' best, with an impressive blend of corporate effectiveness, esprit de corps and extraordinary technical achievement.

Apollo also played a key role in perhaps the greatest of the visions NASA has given the world - that of Earth from space. No images from any of the Apollo missions speak more powerfully than those of Earth rising above the barren Moon, or of Earth alone in space, the Sahara golden, the Antarctic diamond white, the clouds and seas and surfaces between them ineffably rich and complex. Winning a new point of view beyond the surface of Earth has provided nothing aesthetically, spiritually or intellectually more important than the ability to look back at our planet below. NASA, as its more poetically inclined supporters have pointed out before, thus embodies the wisdom of T. S. Eliot's Little Gidding:

We shall not cease from exploration
And the end of all our exploring
Will be to arrive where we started
And know the place for the first time.

This vision from outside is not only inspiring; it is also empowering, providing a fresh way of studying the Earth. As the population dependent on Earth's resources grows, and its perturbations of the planet's atmosphere and ecosystems escalate, studies of the processes being perturbed become ever more valuable.

\section{Mission impoverished}

That is why recent changes to NASA's mission statement are more disturbing than any single cut could be. The goals in the mission statement, developed through a thorough set of consultations earlier this decade, used to begin "to understand and protect our home planet". This imperative is now gone, replaced by a commitment to "pioneering the future".

NASA administrator Michael Griffin argues that the agency is still committed to Earth science through the part of its mission statement that commits it to "scien-

tific discovery", and that what "protect" meant was never clear. For all that, the excision still echoes the only decent scene in

\section{"I hope you don't expect me to save you, 'cause I don't do that any more."}

the movie Superman III: "I hope you don't expect me to save you," that other icon of the American way informs a damsel in distress, "cause I don't do that any more." Except this time there's no artificial kryptonite to pin the blame on. And it's not funny.

It is bad enough that Earth science at NASA has already fallen victim to cuts and cancellations - as has, for what its worth, astrobiology. Now an important rhetorical basis for resisting more attrition has been removed, feeding fears that a real understanding of how the climate works is not high on the administration's agenda. Earth sciences are still well represented in NASA's plans, but they have been symbolically set aside to further a vision that looks only outwards, never back.

This situation should not be allowed to continue. Employees, grantees and others with a stake in the agency should press hard to have the change reversed. A NASA that does not see its interest in the living Earth as essential is as much of a betrayal as a Superman without altruism. 